\title{
CAMPOS DE ATUAÇÃO EM GINÁSTICA: ESTADO DA ARTE NOS PERIÓDICOS BRASILEIROS
}

\author{
FIELDS OF PRACTICE IN GYMNASTICS: A REVIEW OF THE STATE OF THE \\ ART IN BRAZILIAN JOURNALS
}
CAMPOS DE ACTUACIÓN EN GIMNASIA: ESTADO DEL ARTE EN LOS PERIÓDICOS BRASILEÑOS

\section{Michele Viviene Carbinatto*, Wagner Wey Moreira**, Aline Dessupoio Chaves**, Suziane Peixoto Santos ${ }^{* *}$, Regina Rovigati Simões ${ }^{* \star}$}

\begin{abstract}
Palavras-chave Bibliometria. Análise quantitativa. Indicadores de ciência, tecnologia e inovação. Ginástica.

Resumo: 0 objetivo foi identificar, sistematizar e analisar a produção acadêmica sobre ginástica nos periódicos nacionais da área da Educação Física do Web Qualis-Capes dos anos 2000 a junho de 2015. Por meio de indicadores bibliométricos de estudos do tipo estado da arte, identificamos 340 artigos publicados em 61 revistas. Constatamos que a produção na área foi constante nos triênios Capes e que as ginásticas de condicionamento físico tiveram prevalência em $47 \%$ dos estudos, com destaque para a ginástica laboral e publicação em revistas B4, B2 e B1 respectivamente, seguida pelas ginásticas de competição (28\%), cuja frequência por estudos na ginástica artística foi de $55,2 \%$ e prevalência de divulgação em revistas B1, B2 e B4. Por fim, aspectos da saúde, da fisiologia e da pedagogia do esporte foram as temáticas mais utilizadas para discutir os campos de atuação em ginástica.
\end{abstract}

Keywords Bibliometrics. Quantitative analysis. Science, technology and innovation indicators. Gymnastics.

Palabras clave Bibliometría. Análisis cuantitativo. Indicadores de ciencia, tecnología e innovación. Gimnasia.

Abstract: This article identifies and analyzes scientific production about "gymnastics" in Brazilian Physical Education journals in Web Qualis-Capes from 2000 to June 2015. Using state-of-art bibliometric indicators, we found 340 articles published in 61 journals. Production in the area was constant in Capes' three-year-period and fitness-oriented gymnastics prevailed in $47 \%$ of studies - with emphasis on labor gymnastics published in B4, B2 and B1-rated journals respectively - followed by competition gymnastics (28\%) whose frequency in artistic gymnastics studies was $55.2 \%$; they were mainly published in B1 , B2 and B4-rated journals. Finally, aspects of health, physiology and sports pedagogy were the most commonly used topics to discuss fields of practice in gymnastics.

Resumen: El objetivo fue identificar, sistematizar y analizar la producción académica sobre gimnasia en los periódicos científicos nacionales del área de Educación Física en el sistema Qualis-Capes del año 2000 a junio de 2015. A través de indicadores bibliométricos de estudios de tipo estado del arte, identificamos 340 artículos publicados en 61 revistas. Constatamos que la producción en el área fue constante en los trienios Capes y que las gimnasias de condicionamiento físico eran más frecuentes en el $47 \%$ de los estudios, con destaque para la gimnasia laboral y publicados en revistas B4, B2 y B1 , respectivamente, seguidos por las gimnasias de competición (28\% ), cuya frecuencia por estudios en la gimnasia artística fue de un 55,2 \% y prevalencia de divulgación en revistas B1, B2 y B4 . Por último, aspectos de la salud, la fisiología y la pedagogía del deporte fueron los temas más utilizados para la discusión en los campos de actuación en gimnasia.
* Universidade de São Paulo. São Paulo, SP, Brasil.

E-mail: mcarbinatto@ hotmail.com

** Universidade Federal do Triângulo Mineiro. Uberlândia, MG, Brasil. E-mail:weymoreira@uol.com.br

Recebido em: 15-01-2016 Aprovado em: 11-05-2016 (c) (1) (8) Licence 


\section{INTRODUÇÃO}

O avanço das pesquisas em Educação Física (EF) no Brasil foi uníssono a situações favoráveis ao desenvolvimento de estudo na área, como o retorno de pós-graduandos do exterior, organização e sistematização dos eventos científicos e a criação de periódicos, sobretudo nos últimos 25 anos (ROSA; LETA, 2011).

Dentre as incessantes discussões, as reflexões acerca das grandes áreas de conhecimento - Humanas, Biológicas e Exatas - tornaram-se uma inquietação comum na $\mathrm{EF}$, na qual a relação entre as duas primeiras incutiu um ranço dicotômico na área (SAMPAIO, 2014). Longe de aprofundarmos esta questão, o fato é que estudiosos perceberam que a EF passava por uma ampla reformulação que culminou na ampliação nos campos de atuação do profissional. Se antes o mercado de trabalho apontava para o ensino formal e o técnico esportivo em clubes, no final do século XX a expansão se deu nas indústrias (ginástica laboral), academias de ginástica, spas, esportes de aventura e da natureza, acampamentos e hotéis, atendimento personalizado, gestão esportiva, organização de eventos esportivos, e, atualmente, residência multiprofissional em hospitais (NASCIMENTO, 2000; BRASIL, 2005; PRONI, 2010).

Como consequência, observamos a expansão de novos cursos de graduação, na mudança de três para quatro anos na formação inicial, na diferenciação entre licenciatura e bacharelado e, principalmente, na criação de programas de pós-graduação stricto sensu em EF e de grupos de pesquisa (DARIDO; SILVA, 2002; BETTI et al., 2004; COUTINHO et al., 2012).

Esse ritmo de crescimento demandou não apenas uma formação mais qualificada, mas a expansão da geração e da socialização de novos conhecimentos. Frente a esse dinamismo, identificar e revelar as pesquisas na EF passou a indicar os caminhos percorridos e direcionamentos futuros para que a produção se articulasse mais efetivamente com as mudanças inerentes à área. Por este motivo, parecem cada vez mais comuns estudos do tipo "estado da arte", nos quais presunções gerais da EF e/ou específicas a uma temática e/ ou modalidade são anunciadas.

Ademais, os estudos do tipo "estado da arte" podem ser realizados por meio da análise da produção acadêmica científica nos formatos artigos, livros, capítulos de livros, teses e dissertações, resumos expandidos, resumos, grupos de estudos e pesquisas, dentre outras possibilidades.

Rosa e Leta (2011), por exemplo, detectaram que, das 5.628 publicações das pósgraduações em Educação Física, os artigos mais recorrentes foram sobre fisiologia do exercício ( $n=527 / 9,36 \%)$, testes e instrumentos de análise $(n=488 / 8,67 \%)$ e biomecânica $(n=310 / 5,5 \%)$, o que demonstra que as autoras utilizaram temas vinculados a disciplinas usualmente inseridas em currículos de graduação da área.

Quanto às especificidades, nos estudos sobre "lazer", Santos e colaboradores (2014) verificaram 142 artigos publicados na base de dados da Literatura Latino-Americana e do Caribe em Ciências da Saúde (LILACS) e as dividiram em temáticas gerais, como saúde, políticas públicas e esporte. Caregnato et al. (2015) analisaram a predominância entre pesquisas do tipo qualitativa e quantitativa, bem como os procedimentos metodológicos 
utilizados em 53 estudos sobre futsal em teses e dissertações entre os anos de 1996-2012. Ontañon, Duprat e Bortoleto (2012) constataram que a temática circense aparece em 95 produções distribuídas em livros, capítulos de livros e artigos científicos de periódicos indexados no Qualis-Capes e que, por meio da classificação analítica própria, está distribuída em pedagogia, aspectos técnicos, planejamento, dentre outros.

Na temática da ginástica, verificamos que Matioli, Teixeira e Rinaldi (2014) observaram o estado da arte em 431 artigos publicados em seis revistas indexadas na EF sem recorte temporal e identificaram 82 que versavam a temática foco deste trabalho.

Silva et al. (2015) analisaram os trabalhos sobre ginástica publicados nas seis edições do Fórum Internacional de Ginástica Geral pautados nos Grupos de Trabalhos Temáticos (GTTs) disponibilizados pelo Colégio Brasileiro de Ciências do Esporte (CBCE). Ferreira e Teixeira (2014) abordaram o tema em relação à produção com a EF e pessoas com deficiência; Lima et al. (2015) analisaram a produção da pós-graduação de três universidades paulistas em relação às ginásticas artística e rítmica; Sampaio, Kraeski e Farias (2015) sobre a ginástica rítmica. Por fim, Tannús e Simões (2015a; 2015b), Milani, Soares e Bortoleto (2015), Pereira, Andrade e Cesário (2012), Manzato e Bortoleto (2012) e Oliveira et al. (2009) realizaram levantamentos sobre a produção em ginástica em teses, dissertações, monografias e/ou especialização e utilizaram para organização e discussão dos dados a proposta dos campos de atuação da ginástica (competição, condicionamento físico, demonstração, fisioterápica e consciência corporal) elucidada por Souza (1997).

Logo, vincular a produção do estado da arte em ginástica com os campos de atuação do futuro profissional parece ser recorrente e aceito pela comunidade, o que impulsionou a nossa pesquisa, cujo objetivo é realizar o levantamento sobre ginástica nos artigos publicados em revistas indexadas pelo Web-Qualis da Capes (COORDENAÇÃO DE APERFEIÇOAMENTO DE PESSOAL DE NÍVEL SUPERIOR, 2015) de 2000 a junho de 2015 e apontar os campos de atuação mais abordados nas pesquisas.

\section{MÉTODO}

Esse trabalho é um estudo de revisão, do tipo estado da arte, que analisa a produção acadêmica nos periódicos nacionais da área da Educação Física, de 2000 a junho de 2015, sobre a ginástica. Textos sobre o estado da arte são de caráter bibliográfico e contribuem para a sistematização e avaliação da produção acadêmica em determinada área do conhecimento e num período previamente estabelecido, vislumbrando responder aspectos e dimensões que devem ser elucidados (FERREIRA, 2002). Além disso, a análise bibliométrica cresceu consideravelmente nos últimos anos, pois permite visualizar tendências e projeções de um determinado assunto (BASKURT, 2011) e refletir mudanças em diversos níveis (GOKCEOGLU; OKAY; SEZER, 2008).

Para o desenvolvimento da investigação foi feito um levantamento online de todas as revistas da área de Educação Física, classificadas em A1, A2, B1, B2, B3, B4, B5 e C, disponíveis na base de dados do site oficial da Coordenação de Aperfeiçoamento de Pessoal de Nível Superior (Capes), no sistema Web-Qualis, 2007-2009/2010-2012/2013 e 2014, o qual estabelece periodicamente a estratificação. 
Em todas essas buscas foram utilizados os seguintes critérios de inclusão: revistas nacionais com o idioma português, revistas eletrônicas que possuíam ISSN (International Standard Serial Number -Número Internacional Normalizado para Publicações Seriadas).

A opção por um banco de dados virtual justifica-se por possibilitar boa visibilidade, pela facilidade de acesso, por garantir maior abrangência das pesquisas mais recentes sobre o tema e por se tratar de informações disponíveis a qualquer profissional da área.

No primeiro levantamento obtivemos um total de 1981 revistas, sendo 518 nacionais na área. Após essa etapa passamos a identificar os artigos completos e em português presentes nas revistas e que tivessem no título ou nas palavras-chave os seguintes termos: ginástica, academia, fitness e ginasta.

A partir do levantamento no banco de dados, 389 revistas não tinham artigos sobre ginástica, 14 não permitiram que o site fosse aberto, dez estavam repetidas (disponíveis tanto online como impressa), 43 não foram encontradas e uma apresentava apenas os resumos, reduzindo para 610 total de revistas analisadas.

Nestas 61 revistas encontramos 340 artigos, que foram catalogados e analisados em dois momentos distintos, mas, ao mesmo tempo, interligados. 0 primeiro previu 0 diagnóstico das revistas, autorias, instituições que publicaram sobre o assunto, dentre outros aspectos. O segundo, com base na proposta de Souza (1997) constituída por cinco campos de atuação da ginástica (competição, condicionamento físico, demonstração, fisioterápica e consciência corporal) que foram ampliados com as categorias "todas", para aquelas relativas a mais temáticas da ginástica, e a "nenhuma", quando o teor do artigo não se adequava às categorias propostas, como, por exemplo, artigos que indicavam a "ginástica" nos números da bolsa de valores (financeiro).

Vale considerar que, por se tratar de uma pesquisa realizada online, de acesso livre e público, não houve a submissão ao Comitê de Ética e nem a assinatura do Termo de Consentimento Livre e Esclarecido.

\section{RESULTADOS}

O Gráfico 1 (na próxima página) apresenta os campos de atuação dos artigos nas revistas investigadas, classificados de acordo com as cinco categorias de Souza (1997), a saber: ginástica de competição (modalidades competitivas da Federação Internacional de Ginástica - FIG), de condicionamento físico (aquisição ou manutenção da condição física), de demonstração (não competividade, interação social e resgate cultural), fisioterápica (prevenção ou tratamento de doenças), e de consciência corporal (técnicas alternativas), além das denominações "nenhuma", criada para abarcar os artigos que não se enquadravam nas categorias anteriores e "todas" que se refere à abordagem de vários tipos de ginástica.

Notamos que as produções em ginástica são significativamente maiores no campo de atuação relacionado ao condicionamento físico, com destaque para as atividades dentro de academias de ginástica e empresas (indústrias e escritórios). As ginásticas de competição aparecem com um número menor de publicações, no entanto, quando reparamos os estratos dos periódicos, notamos que a divulgação das pesquisas ocorreu em revistas com melhor avaliação pelo sistema Qualis-Capes. 
Gráfico 1 - Relação entre os 340 artigos analisados, os campos de atuação e estratos das revistas em que foram publicados*

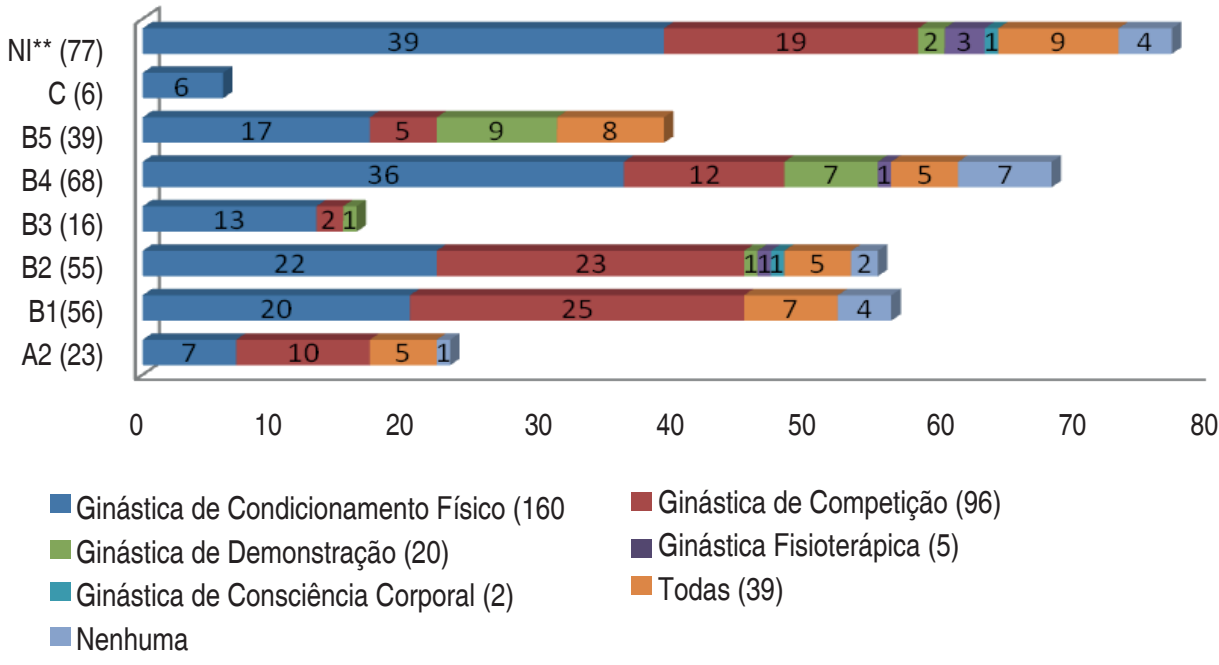

Nota: * Os números entre parênteses referem-se ao valor absoluto. **NI: Não identificado (anterior a 2007 e/ou sem identificação do estrato da revista no ano de publicação do artigo).

Fonte: Coleta de Dados, 2015.

Quando comparamos produções nas modalidades presentes na Federação Internacional de Ginástica (FIG) e, por sua vez, na Confederação Brasileira de Ginástica (CBG), notamos 116 produções nos campos de atuação sobre ginásticas competitivas (82,75\%) e ginásticas demonstrativas (17,25\%) com regularidade em relação à ginástica artística (GA) e rítmica (GR). Preocupante o fato de serem nulos os artigos sobre ginástica de trampolim (GT) e pífios os trabalhos sobre ginástica aeróbica (GAer) e ginástica acrobática (GAcr).

Ademais, as revistas que mais publicaram artigos sobre ginástica de competição ( $n=96)$ foram: Motriz (11/11,45\%), Revista Brasileira de Medicina do Esporte (9/9,37\%), Revista de Educação Física e Esporte (8/8,33\%) e Revista Brasileira de Ciências do Esporte (7/ 7,30\%).

Gráfico 2 - Relação entre as modalidades FIG* e estratos das produções**

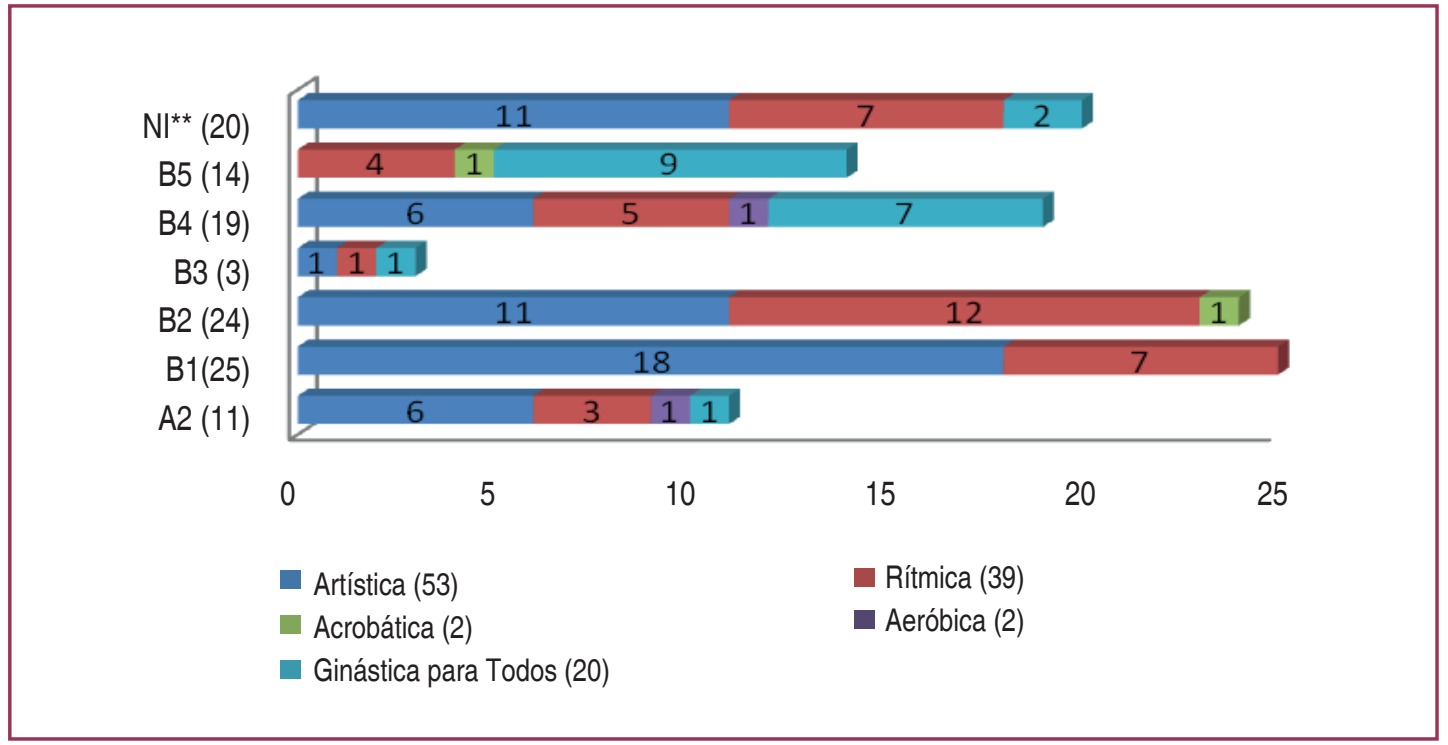

Nota: *Informamos que não identificamos trabalhos com a modalidade Ginástica de Trampolim. **Os números entre parênteses referem-se ao valor absoluto. ${ }^{* *} \mathrm{NI}$ : Não identificado (anterior a 2007 e/ou sem identificação do estrato da revista no ano de publicação do artigo) 
Ao nos debruçarmos sobre os artigos, apresentamos os resultados em relação ao campo de atuação e sua intersecção com áreas científicas de pesquisa, explicitadas no trabalho de Simões et al. (2016). Devido à limitação espacial do artigo, faremos uma discussão pormenorizada apenas das áreas mais prevalentes em cada um dos campos de atuação em ginástica.

Tabela 1 - Relação entre os campos de atuação e temáticas

\begin{tabular}{|c|c|c|c|c|c|c|c|c|c|c|}
\hline & \%气 & $\begin{array}{l}\frac{\frac{\pi}{7}}{8} \\
\frac{0}{\frac{0}{0}} \\
\frac{29}{4}\end{array}$ & $\begin{array}{l}\frac{\pi}{0} \\
\frac{0}{0} \\
\frac{.0}{\mathscr{N}} \\
\frac{1}{2}\end{array}$ & 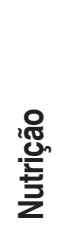 & 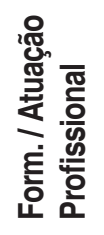 & $\begin{array}{l}\frac{\pi}{0} \\
\frac{0}{0} \\
\frac{\pi}{0} \\
0\end{array}$ & 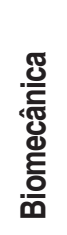 & 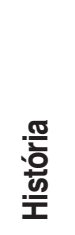 & 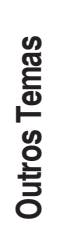 & 要 \\
\hline Cond. Físico & 57 & 27 & 23 & 18 & 18 & 3 & 3 & 3 & 8 & 160 \\
\hline Compet. & 4 & 14 & 14 & 8 & 5 & 25 & 11 & 11 & 4 & 96 \\
\hline Demons. & - & - & - & - & 4 & 11 & - & 1 & 4 & 20 \\
\hline Fisioter. & 5 & - & - & - & - & - & - & - & - & 5 \\
\hline Consc. Corporal & 2 & - & - & - & - & - & - & - & - & 2 \\
\hline Nenhum & - & - & - & - & - & 8 & - & 9 & 1 & 18 \\
\hline Todas & - & 1 & - & - & 5 & 12 & - & 15 & 6 & 39 \\
\hline TOTAL & 68 & 42 & 37 & 26 & 32 & 59 & 14 & 39 & 23 & 340 \\
\hline
\end{tabular}

Por fim, realizamos uma análise detalhada das produções em relação aos estratos das revistas em que os artigos foram publicados e triênios utilizados como avaliação da produção na pós-graduação em Educação Física, tanto no quantitativo geral (Gráfico 3) quando específico das modalidades FIG (Gráfico 4). Ressaltamos que analisamos separadamente as publicações no ano de 2013 e 2014 devido a duas listas publicadas na plataforma Sucupira1. Além disso, a análise das publicações de 2015 se deu pela listagem do ano anterior.

Gráfico 3 - Relação entre a produção científica dos 340 artigos e períodos de publicação*

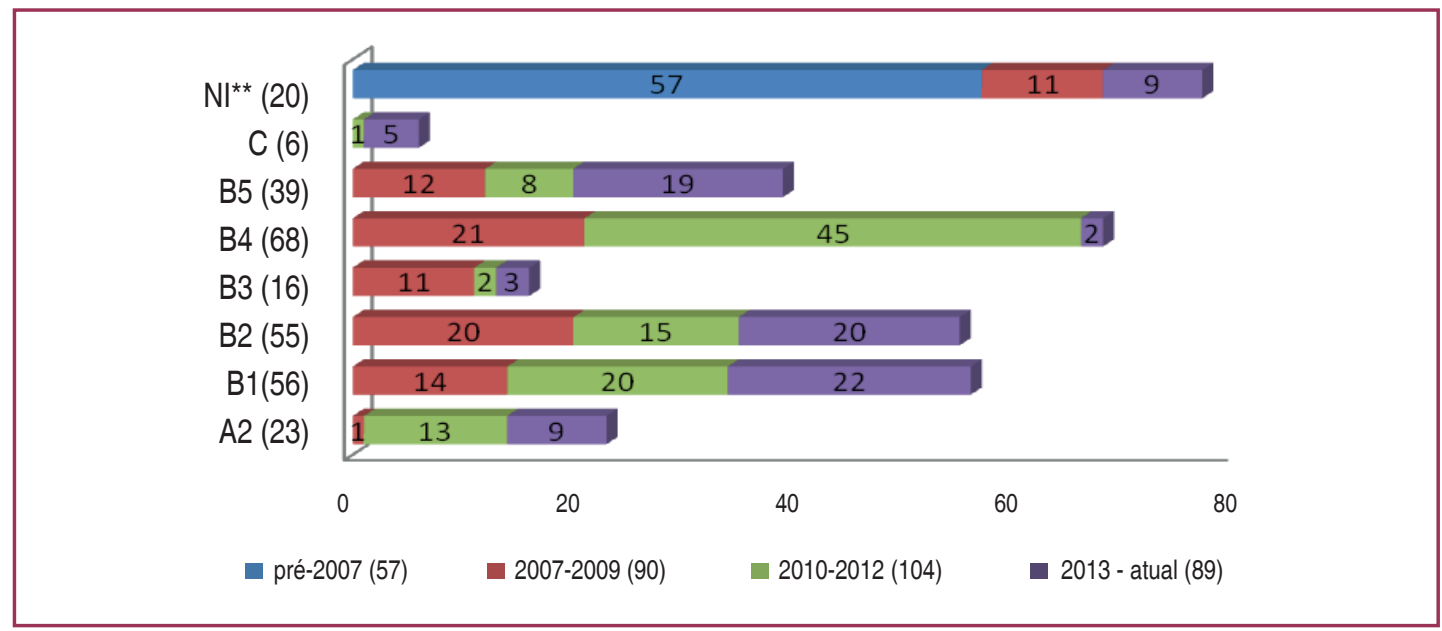

Notas:* Os números entre parênteses referem-se ao valor absoluto. **NI: Não identificado (anterior a 2007 e/ou sem identificação do estrato da revista no ano de publicação do artigo).

Fonte: Coleta de Dados, 2015.

1 A Plataforma Sucupira é uma "ferramenta para coletar informações, realizar análises e avaliações e ser a base de referência do Sistema Nacional de Pós-Graduação (SNPG)" e disponibiliza "em tempo real e com muito mais transparência as informações, processos e procedimentos que a CAPES realiza no Sistema Nacional de Pós-Graduação para toda a comunidade acadêmica". Disponível em: <http:// www.capes.gov.br/avaliacao/plataforma-sucupira>. Acesso em: 3 maio 2016. 
Gráfico 4 - Relação entre a produção científica das modalidades FIG e períodos de publicação*

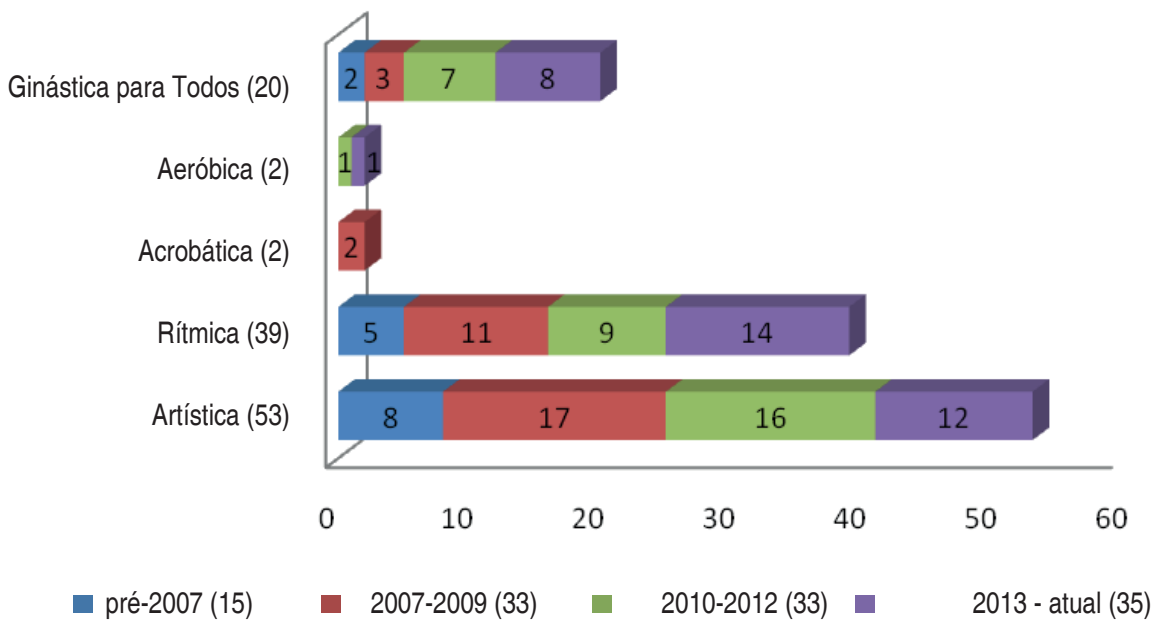

Nota: *Os números entre parênteses referem-se ao valor absoluto.

Fonte: Coleta de Dados, 2015

\section{DISCUSSÃO}

É notável a expansão constante das publicações nos triênios analisados, o que pode ser justificado não apenas pela ampliação de programas de graduação, mas pelo aumento da pós-graduação na Educação Física. As medidas avaliativas destes programas demandam que os pesquisadores atentem para a atualização e publicação em periódicos nacionais e internacionais na área (TANI, 2014). Notamos que as produções sobre ginásticas da FIG também se mantiveram constantes e, até o momento, possuem uma pequena vantagem no último triênio.

O meio de divulgação da produção intelectual das pós-graduações em Educação Física nos anos de 2001 a 2003 foi, primordialmente, livros e anais de eventos, o que pode justificar poucos dados em relação à ginástica neste período (ROSA, LETA, 2011).

No entanto, o fato do Brasil sediar um dos maiores eventos esportivos do mundo, os Jogos Olímpicos, e os resultados expressivos das seleções brasileiras de GR e GA (feminina e masculina) nos fazem pensar se neste triênio a produção não deveria ter se destacado. Claro está que nossa limitação diz respeito ao não levantamento das publicações em revistas internacionais, o que pode levar nosso argumento a outra dimensão (VIVEIROS et al., 2014).

Observamos que a predominância dos artigos produzidos nos periódicos investigados está na categoria Ginástica de Condicionamento Físico, com 47\% (n=160) das produções. Destes, destacam-se a Revista Brasileira de Nutrição Esportiva (16/10\%) seguida pela revista Fitness \& Perfomance Journal e Revista Brasileira de Prescrição e Fisiologia do Exercício, ambas com dez artigos (6,25\%) e concordam com Pereira, Andrade e Cesário (2012).

Pautados nos estudos de Manzato e Bortoleto (2012), nesta categoria inserimos pesquisas sobre ginástica localizada, aeróbica não esportiva, musculação, step, jump, alongamento, dentre outros.

Constatamos que a maior parte dos artigos se relacionou aos temas saúde, fisiologia e psicologia. No primeiro aspecto, dos 57 artigos analisados, $39(68,4 \%)$ voltaram-se às pesquisas 
sobre ginástica laboral, oito (14\%) sobre ginástica em academias, oito (14\%) em musculação e duas $(3,5 \%)$ com práticas orientais. Concluímos que, com a ampliação do conceito de saúde, para além do combate às doenças, expandiram-se as possibilidades de reflexões sobre esta área e seu diálogo com outros campos, o que indica a expressiva vantagem em relação aos demais campos de atuação.

Dos 27 artigos com a intersecção entre ginástica de condicionamento e fisiologia, notamos que $17(62,9 \%)$ tratavam sobre intervenção de programas de treinamento de força e flexibilidade, bem como sobre avaliação da composição corporal dos indivíduos ativos. Interessante notar que, dos 23 artigos sobre psicologia, 13 (56,5\%) faziam alusão sobre a motivação para adesão e permanência em programa sistematizado de exercícios físicos.

Apesar da maior representatividade numérica, os artigos sobre condicionamento físico foram mais recorrentes em revistas nacionais de estratos B4, B2 e B1 respectivamente.

A categoria Ginástica de Competição (96) apresenta preponderância para a Ginástica Artística (53/55,2\%), seguido da Ginástica Rítmica (39/40,6\%), Acrobática (2/2\%) e Aeróbica (2/2\%). Embora a FIG apresente a Ginástica para Todos também com possibilidades competitivas, a análise de Souza (1997) não a prevê nesta categoria e sim na Ginástica de Demonstração. Pontuamos que não ignoramos outros tipos de modalidades ginásticas competitivas como a ginástica rítmica masculina e o TeamGym, por exemplo, mas elas não apareceram em nenhum artigo do nosso levantamento.

De fato, a GA é a modalidade que apresenta maior popularidade no Brasil (VIEIRA; FREITAS, 2007) e a que mais se destaca em produções em cursos de pós-graduação na Educação Física (OLIVEIRA, et al. 2009; TANNÚS; SIMÕES, 2015a; 2015b). Logo, as produções nas demais modalidades parecem seguir a mesma lógica nos artigos: praticamente nulas (MILANI; SOARES; BORTOLETO, 2015).

A limitada produção brasileira em relação às demais modalidades parece seguir uma tendência mundial, visto que Simões et al. (2016) revelaram que na revista Science of Gymnastics Journal, dos 117 artigos publicados entre os anos de 2009 a 2015, apenas três versavam sobre GAcr, um sobre GT e um sobre GAer.

Em relação às temáticas nesta categoria, 25 (26\%) artigos voltaram-se aos aspectos pedagógicos, com destaque para trabalhos sobre iniciação e especialização esportiva, aprendizagem e desenvolvimento motor. Consideramos pertinente informar que nesta categoria observamos cinco trabalhos $(5,2 \%)$ cujo sujeito de pesquisa foi o técnico (e não o sujeito que recebe/realiza o exercício físico). Tal fato denota que há uma preocupação em compreender, entender e discutir assuntos sob o viés analítico daquele que vive o cotidiano esportivo. E, apesar da questão sobre a arbitragem na ginástica ter sido recorrente nas publicações da revista Science of Gymnastics entre os anos de 2009 e 2015 (Simões et al., 2016), no Brasil encontramos somente um artigo sobre 0 assunto.

Nas modalidades competitivas também se destacaram temáticas dos aspectos fisiológicos/treinamento (14/ 14,5\%), psicológicos (14/14, 5\%) e biomecânicos (11/11, 45\%). No primeiro a hegemonia foi da caracterização somatotípica de ginastas e discussões sobre 0 hormônio de crescimento e leptina e o treinamento de GA. No segundo, aspectos motivacionais e distúrbios alimentares e na biomecânica, trabalhos sobre controle corporal, torque ativo e passivo da flexão plantar e análise nos aparelhos solo e argolas foram observados. 
Finalmente, é nítido que a produção nesta categoria é relevante, pois os estratos $B 1$, B2, B4 e inclusive a maior prevalência no estrato A2 demonstram aceitação pela comunidade científica.

As publicações sobre Ginástica de Demonstração perfizeram um total de $20(5,88 \%)$ artigos, sendo que o periódico com destaque considerável foi a revista Conexões (13/65\%). Inclusive, a maior frequência de artigos sobre a Ginástica de Demonstração nas revistas de estratos B5 ocorreu, sobretudo, pelo fato da revista supracitada ter recebido esta avaliação após 0 ano de 2013 no Web-Qualis. A ampliação dos trabalhos após o primeiro triênio de avaliação é fruto da consolidação de eventos científicos e festivais pelo Brasil, sobretudo no estado de São Paulo (ARTUSI, 2008).

Dentre as temáticas mais abordadas, a pedagogia, com produções que saem em defesa da ginástica para todos (GPT) na escola e para pessoas com deficiência e trabalhos sobre formação e atuação profissional (com metodologia voltada ao ambiente universitário) foram prevalentes. É no âmbito universitário que percebemos a ampliação e efetiva massificação da GPT pelo Brasil, visto que as políticas públicas e a própria CBG não apresentam projetos para sua consolidação na sociedade brasileira (BEZERRA et al., 2014; PIZANI et al., 2015).

O fato da GPT não se caracterizar pela competição favorece sua prática em ambientes diversificados e para diferentes públicos, promovendo conhecimentos sobre manifestações culturais de outras regiões, ampliando as relações sociais, favorecendo reflexão sobre a corporeidade (RAMOS; VIANA, 2008; MAROUN, 2015), o que remete à necessária ampliação sobre esta abordagem nas pesquisas nacionais.

Em relação à Ginástica Fisioterápica existem cinco produções (1,5\%), sendo duas na revista Saúde e Pesquisa e Revista Brasileira de Ciência e Movimento (cada) e uma publicação na Revista Mackenzie de Educação Física e Esporte.

Neste item, notamos uma forte referência ao trabalho de reabilitação de pessoas hospitalizadas (2) e pessoas asmáticas (3). Há algumas hipóteses para a pouca produção sobre esta categoria: a. Normalmente, nos cursos de graduação em Educação Física não há disciplinas específicas sobre esse campo de atuação, que inclui reeducação postural global, isostretching, dentre outros (MANZATO; BORTOLETO, 2012); b. A inserção de profissionais da Educação Física em equipes multidisciplinares em hospitais é consideravelmente recente, visto que a Lei 11.129/2005 efetivou a residência cerca de cinco anos depois; c. É usual a produção entre profissionais da fisioterapia e terapia ocupacional, pois aqueles voltam-se com maior ênfase à reabilitação física (VIRTUOSO et al., 2011).

Na categoria Consciência Corporal encontramos dois artigos (0,58\%), um na Revista Latino-Americano de Enfermagem e outro na Revista Brasileira de Saúde Ocupacional. Um dos trabalhos voltou-se à ginástica terapêutica de origem oriental para prevenção de lesões por esforço repetitivo e o outro à intersecção entre a ginástica e a dança. Entendemos que sejam categorias que vão além da nossa área, como a dança, que têm este assunto como prioridade.

Uma categoria que nos chamou atenção, inclusive pelo número expressivo encontrado, é a denominada Todas, com $39(11,47 \%)$ produções. Sendo que Conexões contém dez (25,6\%), Movimento oito (20,5\%) e a Revista de Educação Física sete $(17,9 \%)$ trabalhos. 
As produções elencavam possibilidades variadas para qualquer campo de atuação, como 0 Programa Segundo Tempo, discussão sobre a ginástica no Exame Nacional do Ensino Médio (Enem), festivais de ginástica e trabalhos de estado da arte.

Finalmente, a categoria Nenhuma apresentou 18 (5,3\%) artigos, nas publicações Revista Brasileira de Ciências do Esporte (6/33,3\%), Conexões (4/22,2\%) e Motrivivência (3/16,6\%). Estas não aludiram a um campo de atuação específico, mas apontaram importantes considerações sobre clubes esportivos, a influência de outras nacionalidades na consolidação da Educação Física no Brasil, análise de documentos oficiais acerca do tema ginástica, concepções de corpo, filosofia e aspectos éticos e a ginástica.

\section{CONSIDERAÇÕES FINAIS}

Analisar o estado da arte sobre ginástica no que se refere aos campos de atuação e aos estratos em que encontramos essas publicações nos permite concluir que esta produção, em âmbito nacional, ainda é incipiente e carece de fortalecimento metodológico, reflexivo e expansão, sobretudo nas diferentes modalidades sistematizadas pela FIG.

Além disso, é comum que a experiência anterior na modalidade, ou o contato com ela, eleve a motivação e interesse em aprofundar e pesquisar um determinado assunto (MERIDA; NISTA-PICCOLO; MERIDA, 2008). Portanto, um trabalho em prol da massificação das práticas de ginásticas também pode suscitar a ampliação futura de pesquisas.

Conclui-se, também, que os programas de pós-graduação ainda não se apropriaram de modo significativo da ginástica como área de conhecimento e com suas múltiplas vertentes de estudo.

Nesse contexto, buscar o locus em que a ginástica vem sendo socializada permite evidenciar as conquistas, indicar lacunas e, ao mesmo tempo, chamar a atenção para novas alternativas de investigação.

\section{REFERÊNCIAS}

ARTUSI, Maryland. Diagnóstico dos principais eventos de ginástica geral. 2008. 228f. Dissertação (Mestrado) - Programa de Pós-Graduação em Educação Física, Universidade São Judas Tadeu, São Paulo, 2008.

BASKURT, Oguz. Time series analysis of publication counts of a university: what are the implications? Scientometrics, v. 86, n. 3, p. 645-656, 2011.

BETTI, Mauro et al. A avaliação da Educação Física em debate: implicações para a subárea pedagógica e sociocultural. Revista Brasileira de Pós-Graduação, v. 1, p. 183-194, nov. 2004.

BEZERRA, Ludmila et al. Ginástica na formação inicial em Educação Física: análise das produções científicas. Revista de Educação Física da UEM, Maringá, v. 25, n. 4, set./dez. 2014.

BRASIL. Ministério da Saúde. Residência Multiprofissional. Disponível em: <http://portal.mec.gov. br/residencias-em-saude/residencia-multiprofissional >. Acesso em: 15 nov. 2015.

COORDENAÇÃO DE APERFEIÇOAMENTO DE PESSOAL DE NÍVEL SUPERIOR. Plataforma Sucupira. Periódicos Qualis. Disponível em: <https://sucupira.capes.gov.br/sucupira/public/consultas/ coleta/veiculoPublicacaoQualis/listaConsultaGeralPeriodicos.jsf>. Acesso em: 9 jul. 2016. 
CAREGNATO, André et al. A produção científica sobre futsal: análise de dissertações e teses publicadas no portal da Capes entre 1996-2012. Motrivivência, v. 27, n. 46, p. 15-34, dez. 2015.

COUTINHO, Renato et al. Análise da produção de conhecimento da educação física brasileira sobre 0 cotidiano escolar. Revista Brasileira de Pós-Graduação, v. 9, n. 17, p. 491 - 516, jul. 2012.

DARIDO, Suraya Cristina; SILVA, Eduardo Vinicius Mota e. O papel das disciplinas esportivas na formação profissional em Educação Física. In: MOREIRA, Wagner Wey; SIMÕES, Regina (Org.).

Esporte como fator de qualidade de vida. Piracicaba: UNIMEP, 2002. p. 151-162.

FERREIRA, Norma Sandra de Almeida. As pesquisas denominadas "estado da arte". Educação e Sociedade, v. 23, n. 79, p. 257-272, ago. 2002.

FERREIRA, Fernanda; TEIXEIRA, David. Atualidade da produção científica brasileira sobre o ensino da ginástica para pessoas com deficiência: contribuições para Educação Física escolar. In: FÓRUM INTERNACIONAL DE GINÁSTICA GERAL, 7., Campinas, 2014. Anais... São Paulo, 2014. p. 283287. Disponivel em: <http://www.forumgpt.com/arquivos/anais/07-forum-internacional-de-ginasticageral-2014pdf>. Acesso em: 6 jan. 2016.

GOKCEOGLU, Candan; OKAY Aral; SEZER, Ebru. International earth science literature from Turkey 1970-2005: trends and possible causes. Scientometrics, v. 74, n. 3, p. 409-423, 2008.

LIMA, Letícia; et al. UNESP-UNICAMP-USP: A produção científica sobre a ginástica artística e rítmica de competição na pós-graduação. Revista Brasileira de Educação Física e Esporte, São Paulo, v. 29, n. 8, p. R60, nov. 2015.

MANZATO, Andréia da Silva; BORTOLETO, Marco Antônio Coelho. Acervos em Ginástica: a biblioteca da FEF/UNICAMP. Conexões, Campinas, v. 10, p. 28-38, dez. 2012. Número especial.

MATIOLI, Jonas Spaciari; TEIXEIRA, Fabiane Castilho; BARBOSA-RINALDI, leda Parra. A ginástica no Brasil: apontamentos sobre a produção do conhecimento. In: FÓRUM INTERNACIONAL DE GINÁSTICA GERAL, 7., Campinas, 2014. Anais... São Paulo, 2014. v. 1. p. 93-98. Disponível em: $<$ http://www.forumgpt.com/arquivos/anais/07-forum-internacional-de-ginastica-geral-2014pdf $>$. Acesso em: 10 jan. 2016.

MAROUN, Kalyla. Ginástica geral e Educação Física escolar: uma possibilidade de intervenção pautada na diversidade cultural. Revista Contemporânea de Educação, Rio de Janeiro, v. 10, n. 19, p. 40-54, jan./jun. 2015.

MERIDA, Fernanda; NISTA-PICCOLO, Vilma; MERIDA, Marcos. Redescobrindo a ginástica acrobática. Movimento, Porto Alegre, v. 14, n. 2, p. 155-180, maio/ago. 2008.

MILANI, Camila; SOARES, Daniele; BORTOLETO, Marco Antônio Coelho. Ginástica: a produção dos estudantes de graduação e especialização da faculdade de Educação Física da UNICAMP 19852014. Coleção Pesquisa em Educação Física, Jundiaí, v. 14, n. 3, p. 89-98, 2015.

NASCIMENTO, Juarez Vieira. Realidade e perspectivas do mercado de trabalho em Educação Física para o século XXI. Caderno de Educação Física, v. 1, n. 1, p. 117-136, 2000.

OLIVEIRA, Maurício Santos et al. Pesquisa em ginástica: a produção da pós-graduação da Faculdade de Educação Física da Unicamp. Conexões, v. 7, p. 41-60, 2009.

ONTAÑÓN, Teresa; DUPRAT, Rodrigo; BORTOLETO, Marco Antônio Coelho. Educação Física e atividades circenses: 0 estado da arte. Movimento, Porto Alegre, v. 18, n. 2, p. 149-168, abr./jun. 2012.

PEREIRA, Ana; ANDRADE Thaís; CESÁRIO, Marilene. A produção do conhecimento científico em Ginástica. Conexões, v. 10, p. 56-79, 2012.

PIZANI, Juliana et al. As disciplinas gímnicas nos cursos de licenciatura em Educação Física do estado do Paraná. Conexões, v. 13, p. 58-76, maio 2015. Número especial.

PRONI, Marcelo Weishaupt. Universidade, profissão Educação Física e o mercado de trabalho.

Motriz, v. 16, n. 3, p. 788-798, set. 2010. 
RAMOS, Eloiza da Silva Honório; VIANA, Helena Brandão. A importância da ginástica geral na escola e seus benefícios para crianças e adolescente. Revista Movimento e Percepção, v. 9, n. 13, p. 190199, jul./dez. 2008.

ROSA, Suely; LETA, Jacqueline. Tendências atuais da pesquisa brasileira em Educação Física. Parte 2: a heterogeneidade epistemológica nos programas de pós-graduação. Revista Brasileira de Educação Física e Esporte, v. 25, n. 1, p. 7-18, jan./mar. 2011.

SAMPAIO, Gabriela; KRAESKI, Ana Claudia; FARIAS, Go. Análise da produção científica relacionada à ginástica rítmica na base de dados Lilacs. Revista Brasileira de Educação Física e Esporte, v. 29, n.8, p. R41, nov. 2015.

SAMPAIO, Tania. Desafios e perspectivas para a divulgação da pesquisa em Educação Física: um processo de construção. Revista Brasileira de Ciências do Esporte, v. 36, n. 4, p. 733-739, out./ dez. 2014.

SANTOS, Priscila Mari et al. Abordagens sobre o lazer na literatura latino-americana em Ciências da Saúde: um revisão na base de dados Lilacs. Revista Brasileira de Estudos do Lazer, v. 1, n. 2, p. 117-139, ago. 2014.

SILVA, Deisy et al. $O$ estado da arte da ginástica nos Anais do Fórum Internacional de Ginástica Geral de 2001 a 2012. Conexões, v. 13, p. 211-229, 2015.

SIMÕES, Regina et al. A produção acadêmica sobre ginástica: estado da arte dos artigos científicos. Revista Brasileira de Educação Física e Esporte, v. 30, n. 1, p. 183-198. 2016.

SOUZA, Elizabeth Paoliello Machado de. Ginástica geral: uma área do conhecimento da Educação Física. 1997. 163f. Tese (Doutorado) - Programa de Pós Graduação em Educação Física, Universidade Estadual de Campinas, Campinas, 1997.

TANI, Go. Editoração de periódicos em Educação Física/Ciências do Esporte: dificuldades e desafios. Revista Brasileira de Ciências do Esporte, Florianópolis, v. 36, n. 4, p. 715-722, out./dez. 2014.

TANNÚS, Fernanda; SIMÕES, Regina. Ginástica: a produção científica nas teses de doutorado. Revista Brasileira de Educação Física e Esporte, v. 29, n.8, p.R57, nov. 2015 a.

TANNÚS, Fernanda; SIMÕES, Regina. 0 estado da arte nas dissertações de mestrado da educação e educação física: o caso da Ginástica. Revista Brasileira de Educação Física e Esporte, 29, n. 8, p. R57, nov. 2015b.

VIEIRA, Silvia; FREITAS, Armando. 0 que é ginástica artística. Rio de Janeiro: Casa da Palavra, 2007.

VIRTUOSO, Janeisa et al. A produção de conhecimento em fisioterapia: análise de periódicos nacionais (1996 a 2009). Fisioterapia em Movimento, v. 24, n. 1, p. 173-180, jan./mar. 2011.

VIVEIROS, Luís et al. Ciência do Esporte no Brasil: reflexões sobre o desenvolvimento das pesquisas, o cenário atual e as perspectivas futuras. Revista Brasileira de Educação Física e Esporte, v. 29, n.1, p. 163-175, jan./mar. 2015.

Apoio: FAPEMIG (Fundo de Amparo à Pesquisa do Estado de Minas Gerais). CNPq (Conselho Nacional de Desenvolvimento Científico e Tecnológico).

Agradecimento: Os autores agradecem a primorosa contribuição da Profa. Ana Laura Coelho na coleta e organização dos dados. 